\title{
フィードバック装置を用いた薬学部一年生における一次救命処置実習の学修効果
}

\author{
丸山桂司, ${ }^{*, a, b}$ 竹内保男, $b$ 大藏直樹, ${ }^{c}$ 根岸文子, ${ }^{d}$ 秋山 暢, $b, e$ 金子一郎 $b, f$
}

\section{Analysis of Basic Life Support Training Provided to Pharmacy Students Using Feedback Device}

\author{
Keiji Maruyama, ${ }^{*, a, b}$ Yasuo Takeuchi, ${ }^{b}$ Naoki Ohkura, ${ }^{c}$ Fumiko Kihara-Negishi, ${ }^{d}$ \\ Nobu Akiyama, ${ }^{b, e}$ and Ichiro Kaneko ${ }^{b, f}$ \\ a Research Center for the Promotion of Pharmacy and Pharmaceutical Practice, School of Pharma-Sciences, Teikyo University; \\ 2-11-1 Kaga, Itabashi-ku, Tokyo 173-8605, Japan: ${ }^{b}$ Teikyo Simulation Education Research Center, Teikyo University; \\ 2-11-1 Kaga, Itabashi-ku, Tokyo 173-8605, Japan: 'Department of Medical and Pharmaceutical Sciences, School of \\ Pharma-Sciences, Teikyo University; 2-11-1 Kaga, Itabashi-ku, Tokyo 173-8605, Japan: dDepartment of Life and \\ Health Sciences, School of Pharma-Sciences, Teikyo University; 2-11-1 Kaga, Itabashi-ku, Tokyo 173-8605, \\ Japan: ${ }^{~}$ Department of Internal Medicine, School of Medicine, Teikyo University; 2-11-1 Kaga, Itabashi-ku, \\ Tokyo 173-8605, Japan: and fDepartment of Emergency Medicine, School of Medicine, Teikyo \\ University; 2-11-1 Kaga, Itabashi-ku, Tokyo 173-8605, Japan.
}

(Received January 7, 2020; Accepted March 13, 2020)

\begin{abstract}
The quality of chest compression affects survival after sudden cardiac arrest, particularly when it occurs out of hospital. Pharmacy students should acquire basic life support skills as part of the model core curriculum of pharmacy education. Here, we trained first-year students at the Faculty of Pharmacy to deliver cardiopulmonary resuscitation and used a manikin with a real-time feedback device that quantified chest compression skills. Students were classified into shallow compressions (SC; $<50 \mathrm{~mm}$ ) and deep compressions (DC; $\geq 50 \mathrm{~mm}$ ) groups based on the depth of chest compressions measured prior to training. After training, the mean compression depth $(\mathrm{mm})$ was significantly shallower for the SC, than the DC group and many students in the SC group did not reach a depth of $50 \mathrm{~mm}$. Similarly, students were classified into slow compression rate $(\mathrm{SR} ; \leq 120 / \mathrm{min})$ and rapid compression rate $(\mathrm{RR} ;>120 / \mathrm{min})$ groups based on the results of training in the rate of chest compressions. Significant differences in mean compression rates were not found between the groups. However, correct compression rate (\%), the percentage of maintaining 100-120 compression/min was significantly higher in the SR, than in the RR group. Chest compression rates correlated with compression depth, and chest compression tended to be too shallow in group that was too fast. The quality of chest compression might be improved by delivering chest compressions at a constant rate within the recommended range.
\end{abstract}

Key words — pharmacy education; chest compression quality; cardiopulmonary resuscitation; feedback device; basic life support; model core curriculum

緒言

薬学教育モデルカリキュラムにおいて, 薬学生は シミュレータを用いて一次救命処置の学修を行うこ ととされている. ${ }^{1)}$ 一次救命処置の技術を身につけ ることは，薬剤師が患者や地域住民の生命の危機的 状況に対処するために必要不可欠なものであり，学

$a$ 帝京大学薬学部薬学実習推進研究センター, $b$ 帝京大 学シミュレーション教育研究センター, c 帝京大学薬学 部医療薬学講座, $d$ 帝京大学薬学部生命薬学講座, $e$ 帝 京大学医学部内科学講座, $f$ 帝京大学医学部救急医学講 座

*e-mail: kei-maru@pharm.teikyo-u.ac.jp
生のうちから学修する重要性が高いと思われる。ま た，わが国は高齢化が進み，薬剤師による在宅での 訪問指導の機会が増えていることから, 薬剤師が居 宅で心肺停止の患者に遭遇する可能性も高いと考え られる。 日本では年間 12 万人以上が心肺停止で救 急搬送されており，そのうち心原性の傷病者は 7 万 8 千人を超え, ${ }^{2)}$ 心肺停止の $70 \%$ 以上が自宅で起き ている. ${ }^{3)}$ 心肺停止後の救命の可能性は時間ととも に低下するが，救急隊の到着までの短時間であって も救命処置を行えば救命率は高くなる. ${ }^{4)}$ 傷病者の 救命率を高めるためには, 質の高い胸骨圧迫を実施 する必要があり，その基準は Japan Resuscitation Council (JRC) 蘇生ガイドライン 20155)において, 


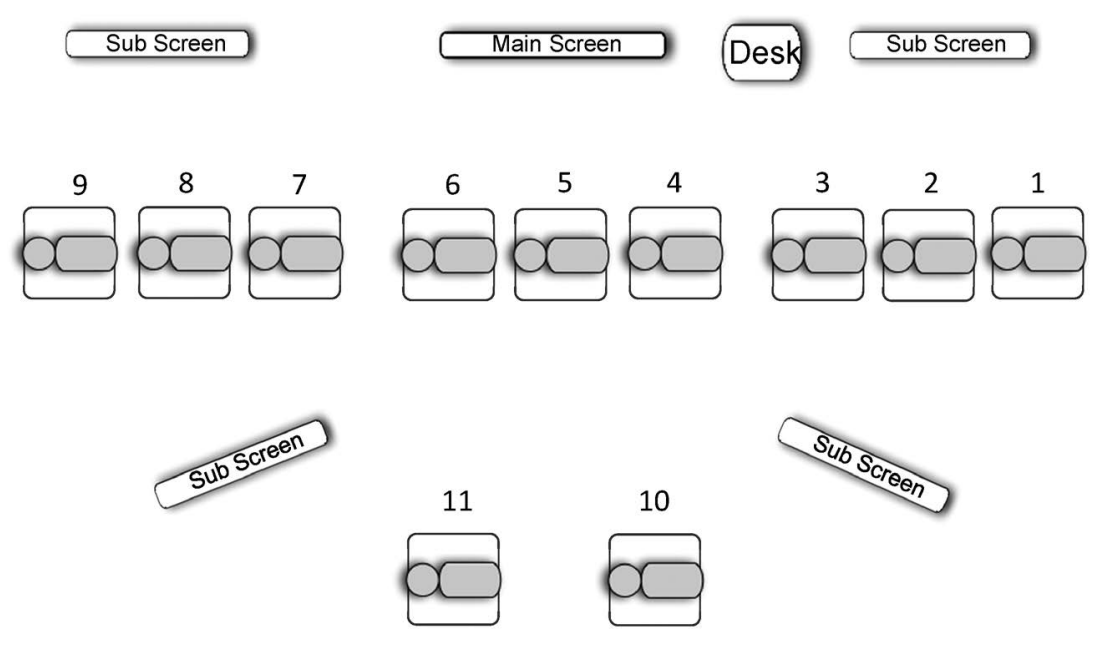

Fig. 1. Layout of Cardiopulmonary Resuscitation Manikins in Simulation Room Students were assigned to 11 groups of 3-4 each. One instructor was assigned to each group.

(1) 胸骨圧迫の部位は胸骨下半分, (2) 深さは 50-60 mm,

(3) テンポは 100-120 回/分, (4) 完全な圧迫解除,

(5) 圧迫中断時間は 10 秒以内を推奨している。薬剤 師や薬学生が行う一次救命処置実習においては，質 の高い胸骨圧迫を修得できたかを評価する必要があ ると考えられるが，多くの薬系大学で実施された一 次救命処置実習に関する報告は学生の意識調査や知 識を問うものが多く, ${ }^{6-8)}$ 客観的技術評価に関する 報告はほとんどない。 今回われわれは，薬学部 1 年 生を対象にリアルタイムフィードバック装置を用い た一次救命処置の実習を実施し, 実習前後の学生の 胸骨圧迫の深さ及びテンポを解析することにより, 質の高い胸骨圧迫修得のための効果的な指導方法に ついて検討した。

\section{方法}

1. 対象と教育プログラム 帝京大学薬学部 1 年生のうち, デー夕解析が可能であった 214 名を対 象とした．学生は 1 班 3-4 名とし， 1 班につき 1 名 の指導教員を配置した，指導教員は，薬学部の教員 とした。実習 1 日あたりの学生数は約 40 名とし, 2018 年 10 月 30 日-11月 20 日の間に実習を行っ た。実習における学生配置図を Fig. 1 に示した。 指導教員による教育効果の差異を減らすために, 学 生実習実施前に教員を対象とした講習会を実施し, 指導教員は全員指導方法について医師，救急救命 士，看護師又はアメリカ心臓協会（American Heart Association；AHA）BLS インストラクター資格を
持つ薬剤師から指導を受けた。ささらに，複数の学生 に胸骨圧迫と人工呼吸の正しい手技やテンポを同じ レベルで修得させるために，実習中には指導教員が 担当の班でデモンストレーションは行わず，本学シ ミュレーション教育研究委員会で作成した DVD 教 材を用いて「傷病者の発見・安全確認から胸骨圧迫 まで」「胸骨圧迫」，「ポケットマスクを用いた人工 呼吸の基本的手技」及び「AED（自動体外式除細 動器）の使用方法」を学生に提示した。なお, DVD の内容はインストラクターがマネキンに対し 行う手技に関するデモンストレーションを中心とし た。実習内容は，学修到達目標等のイントロダク ション (10 分)，成人に対する胸骨圧迫（DVD 閲 覧 5 分, 実技 20 分), 人工呼吸 (DVD 閲覧 5 分, 実技 10 分)，胸骨圧迫と人工呼吸の組み合わせ（実 技 10 分)，傷病者の呼吸と脈の確認（DVD 閲覧 5 分, 実技 5 分), 傷病者の発見から胸骨圧迫と人工 呼吸の組夕合わせ（実技 15 分）, AED の使用方法 (DVD 閲覧 5 分, 実技 10 分)，傷病者発見から AED によるショックまで（実技 20 分），授業単位 認定のための実技試験（20 分）とした.

実技実習は，レールダル社製レサシアン with $\mathrm{QCPR}^{\mathrm{TM}}$ を用いて実施した。圧迫の適切な深さや テンポ，圧迫後の完全に胸壁を戻す手技のフィード バック等は， $\mathrm{QCPR}^{\mathrm{TM}}$ を用いてリアルタイムで 行った。また，テンポに関する学修には，メトロ ノーム（110 回/分）を併用した.

2. 解析項目の記録 実習前に DVD 教材を用 


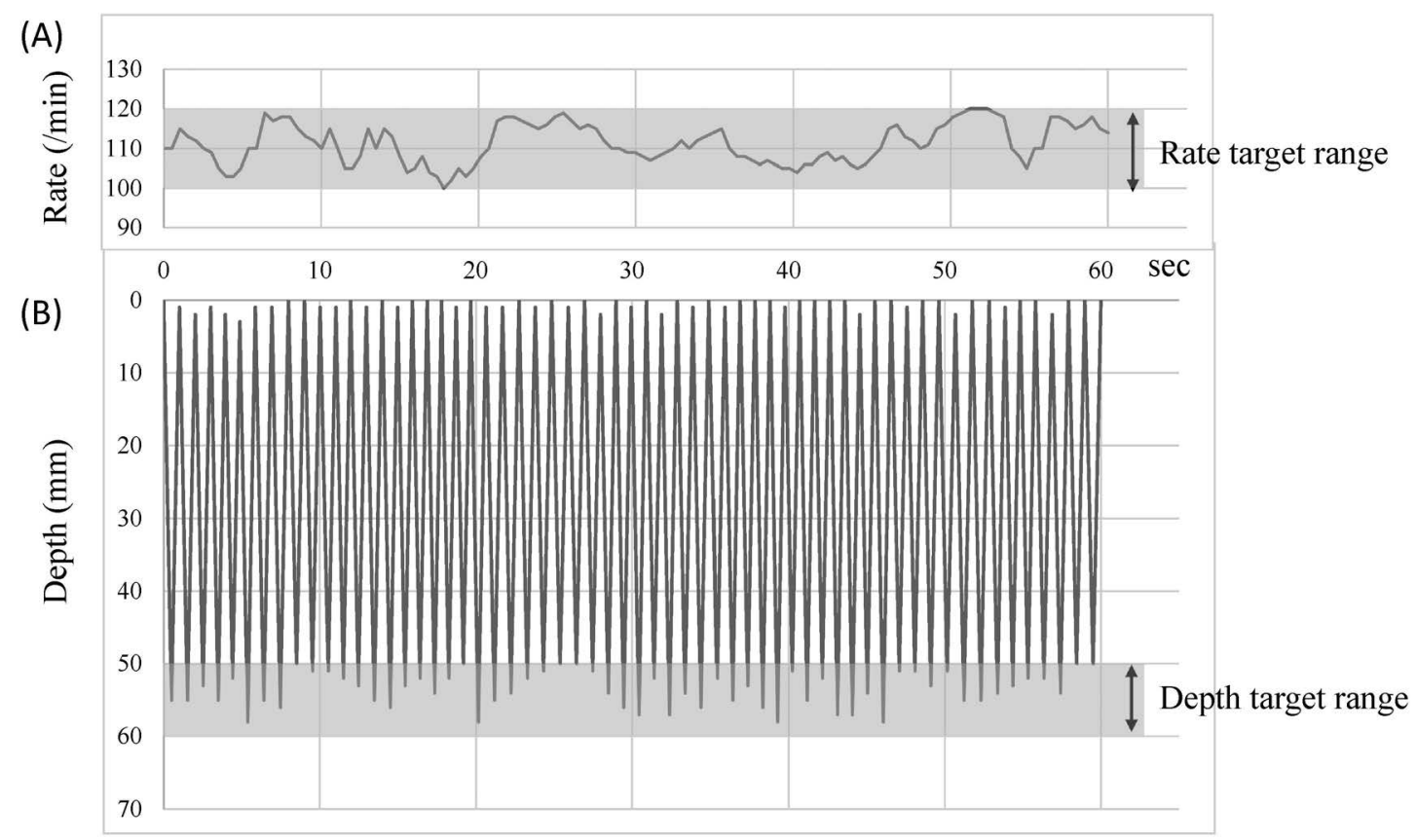

Fig. 2. Adequate Depth and Rate of Chest Compressions

Ideal chest compression depth and rate recommended in the Japan Resuscitation Council (JRC) resuscitation guidelines 2015 is 50-60 mm and 100-120 per minute, respectively. Compression rate (A) and depth (B) .

いて胸骨圧迫方法・胸骨圧迫部位を学生に提示し た. 説明終了後, 1 分間の胸骨圧迫のみの評価を実 施し，解析項目として圧迫の深さ及びテンポを記録 した（Fig. 2)，適切な胸骨圧迫の深さ及びテンポ は, JRC 蘇生ガイドライン 20155) に基づき, 50-60 mm 及び 100-120回/分とした。記録中は，指導者は手 技の修正，フィードバックを行わず，記録終了後に 修正ポイントについてフィードバックを行つた。実 習中は，リアルタイムフィードバック装置を用いて 手技の修正点をリアルタイムで指導した。実習終了 後の記録は実技試験終了後に行い，実習前の記録と 同様，指導者による介入は行わずに解析項目を記録 した。また，胸骨圧迫の有効率を「(50-60 mm で 圧迫できた圧迫数) / (1 分間当たりの全圧迫数 $) \times$ 100」により算出した。同様に，1 分間当たりに 100-120 回/分のテンポを維持できた割合を圧迫の テンポの有効率とした。 $\chi^{2}$ 検定には IBM 社製 SPSS Statistics 24，その他の検定にはエクセル統計 2010 を用い，有意水準は 5\%とした。

3. 実習前後における胸骨圧迫の質の比較 実 習前の学生は, 胸骨圧迫の適切な力加減を修得して いないため，圧迫が浅すぎる学生と十分な深さで実 施できる学生が混在している，本研究では，実習前 に圧迫の浅い学生群と十分に圧迫できた学生群で手
技の習熟度に特徵的な違いがあるかを明らかにする ため，実習前の深さを 2 つ群に分類した。 JRC 蘇生ガイドラインにおいて，深さは $50 \mathrm{~mm}$ 以上圧 迫することが推奨されているため，分類は $50 \mathrm{~mm}$ 未満群 [shallow compressions (SC) 群] と $50 \mathrm{~mm}$ 以上群 [(deep compressions (DC) 群] とし, 実 習後における各群の圧迫の深さの質を比較した。同 様に，テンポについては 120 回/分が上限に設定さ れていることから，120回/分以下群［(slow compression rate（SR）群］と 120 回/分超群［(rapid compression rate（RR）群］に学生を分類し，実習 後のテンポの質を評価した.

4. 倫理的配慮収集した情報は, 研究対象者 の個人情報の保護を十分に行ったうえ，オプトアウ トにより研究についての情報を公開した。本研究 は, 帝京大学倫理審査委員会により承認を受けたも のである（承認番号：帝倫 19-048）。

\section{結果}

1. 胸骨圧迫の深さ 実習前の圧迫の深さの測 定值を解析したところ，SC 群及び DC 群の学生数 はそれぞれ 130 名及び 84 名であった（Table 1). 実習後の胸骨圧迫の深さ (Mean compression depth) は，SC 群で $49.2 \pm 4.9 \mathrm{~mm}$ であり， DC 群の 53.2 
Table 1. Comparison of Chest Depth between Shallow and Deep Chest Compressions after Training

\begin{tabular}{|c|c|c|c|}
\hline & \multicolumn{2}{|c|}{ Classification of skill before training } & \multirow{2}{*}{$p$} \\
\hline & $\mathrm{SC}$ group & DC group & \\
\hline \multicolumn{4}{|l|}{ Total } \\
\hline Students (\%) & $100(130 / 130)$ & $100(84 / 84)$ & \\
\hline Mean compression depth (mm) & $49.2 \pm 4.9$ & $53.2 \pm 4.5$ & $<0.01^{\dagger}$ \\
\hline Correct compression depth (\%) & $46.7 \pm 33.4$ & $66.0 \pm 27.5$ & $<0.01^{\dagger}$ \\
\hline \multicolumn{4}{|l|}{ Adequate depth $(50-60 \mathrm{~mm})$} \\
\hline Students (\%) & $49.2(64 / 130)$ & $78.6(66 / 84)$ & \\
\hline Mean compression depth (mm) & $52.8 \pm 2.6$ & $54.6 \pm 2.9$ & $<0.01^{\dagger}$ \\
\hline Correct compression depth (\%) & $75.8 \pm 19.9$ & $77.2 \pm 18.2$ & 0.67 \\
\hline \multicolumn{4}{|l|}{ Inadequate depth $(<50 \mathrm{~mm})$} \\
\hline Students（\%） & $50.0(65 / 130)$ & $19.0(16 / 84)$ & \\
\hline Mean compression depth (mm) & $45.4 \pm 3.5$ & $46.4 \pm 3.3$ & 0.31 \\
\hline Correct compression depth (\%) & $18.6 \pm 14.0$ & $26.3 \pm 12.8$ & $<0.05^{*}$ \\
\hline \multicolumn{4}{|l|}{ Inadequate depth $(>60 \mathrm{~mm})$} \\
\hline Students（\%） & $0.8(1 / 130)$ & $2.4(2 / 84)$ & \\
\hline Mean compression depth (mm) & 61 & 61 & \\
\hline Correct compression depth (\%) & 12.0 & 14.5 & \\
\hline
\end{tabular}

Correct compression depth $(\%)=$ number of sufficiently deep compressions/number of total compressions $\times 100$. $p$ values were calculated using Welch $t$-tests. Data are shown as means \pm S.D. or $\%(n)$. SC, shallow compressions $(<50 \mathrm{~mm})$; DC, deep compressions $(\geq 50 \mathrm{~mm}) .{ }^{*}$ and ${ }^{\dagger}$, significantly different.

$\pm 4.5 \mathrm{~mm}$ に比べ有意に浅かった。 また，圧迫の深 さの有効率（Correct compression depth）も SC 群 及び DC 群でそれぞれ $46.7 \pm 33.4 \%$ 及び $66.0 \pm$ $27.5 \%$ であ，SC 群で有意に低かった。この差 は，各群において適切な深さ $(50-60 \mathrm{~mm})$ での胸 骨圧迫を修得できた学生（Adequate depth）の割合 に依存しており，実習後の DC 群では $78.6 \%, S C$ 群では $49.2 \%$ であった。また，適切な圧迫を修得 できた学生における圧迫の深さの有効率は両群とも $75 \%$ を超えており，DC 群及び SC 群で圧迫の質に 有意な差はみられなかった。一方，実習後に圧迫の 深さが $50 \mathrm{~mm}$ に達しなかった学生 [Inadequate depth $(<50 \mathrm{~mm})]$ は, SC 群で $50.0 \%, \mathrm{DC}$ 群で 19.0\%であった.

2. 圧迫のテンポ 実習前の圧迫のテンポの測 定值を解析したところ，SR 群及び RR 群の学生数 はそれぞれ 115 名及び 99 名であった（Table 2). 実習後における圧迫のテンポ（Mean compression rate）は SR 群及び RR 群で，いずれもガイドライ ンで推奨される圧迫のテンポの範囲内であった。し かし，テンポの有効率 (Correct compression rate) を比較すると各群で差が認められ， RR 群では 59.8 $\pm 36.7 \% ， \mathrm{SR}$ 群では $82.8 \pm 28.6 \%$ であり，RR 群
で有意に低かった。これは，実習後に適切なテンポ で胸骨圧迫できた学生（Adequate rate）の割合に 関連しており, SR 群では $85.2 \%$ の学生が適切なテ ンポを修得した一方，RR 群では $61.6 \%$ に留まって いた。ささらに，実習後に適切なテンポで胸骨圧迫を 実施できた学生の有効率は，SR 群と RR 群で有意 な差が観察され，SR 群は $93.6 \pm 9.8 \% ， \mathrm{RR}$ 群では $85.5 \pm 15.6 \%$ であった。これは，RR 群では， 1 分 間の胸骨圧迫におけるテンポが推奨範囲内で一定し てないないことを示している，また，RR 群の学生 のうち，テンポを改善できなかった学生 [Inadequate rate group $(>120 / \mathrm{min})]$ は 38.4\%であり, SR 群の $12.2 \%$ に比べ高かった.

3. 胸骨圧迫の深さとテンポの関連性実習後 の胸骨圧迫の深さとテンポの関連性を Table 3 に示 した。実習後に測定した胸骨圧迫の深さとテンポと の関係をイエーツの補正を用いた $\chi^{2}$ 検定で分析し たところ， $\chi^{2}(1)=6.600, p<0.05$ であり，圧迫の 深さとテンポに関連がある可能性が示された。 さら に，調整済み残差分析を行ったところ，テンポが 120 回/分以下の学生群では, 圧迫の深さが $50 \mathrm{~mm}$ 以上の学生数が有意に多く, テンポが速すぎる 120 回/分超の学生群では圧迫の深さが $50 \mathrm{~mm}$ 未満の学 
Table 2. Comparison of Compression Rate Quality between Slow and Fast Groups after Training

\begin{tabular}{lccc}
\hline \hline & \multicolumn{2}{c}{ Classification of skill before training } & \multirow{2}{*}{$p$} \\
\cline { 2 - 3 } & SR group & RR group & \\
\hline Total & & & \\
Students $(\%)$ & $100(115 / 115)$ & $100(99 / 99)$ & \\
Mean compression rate $(/ \mathrm{min})$ & $114.4 \pm 6.4$ & $119.2 \pm 6.8$ & $<0.01^{\dagger}$ \\
Correct compression rate $(\%)$ & $82.8 \pm 28.6$ & $59.8 \pm 36.7$ & $<0.01^{\dagger}$ \\
\hline Adequate rate $(100-120 / \mathrm{min})$ & & & \\
Students $(\%)$ & $85.2(98 / 115)$ & $61.6(61 / 99)$ & \\
Mean compression rate $(/ \mathrm{min})$ & $113.6 \pm 4.3$ & $115.1 \pm 4.6$ & $<0.05^{*}$ \\
Correct compression rate $(\%)$ & $93.6 \pm 9.8$ & $85.5 \pm 15.6$ & $<0.01^{\dagger}$ \\
\hline Inadequate rate $(>120 / \mathrm{min})$ & & & \\
Students $(\%)$ & $12.2(14 / 115)$ & $38.4(38 / 99)$ & 0.33 \\
Mean compression rate $(/ \mathrm{min})$ & $124.5 \pm 3.4$ & $125.6 \pm 4.4$ & 0.61 \\
Correct compression rate $(\%)$ & $22.0 \pm 22.1$ & $18.6 \pm 18.3$ & \\
\hline Inadequate rate $(<100 / \mathrm{min})$ & & & \\
Students $(\%)$ & $2.6(3 / 115)$ & $0(0)$ & - \\
Mean compression rate $(/ \mathrm{min})$ & $93.7 \pm 3.2$ & - & - \\
Correct compression rate $(\%)$ & $14.0 \pm 7.8$ & - & - \\
\hline
\end{tabular}

Correct compression rate (\%): proportion of adequate compression rates for one minute. $p$ values were calculated using Welch $t$-tests. Data are shown as means \pm S.D. or $\%(n)$. SR, slow compression rate $(\leq 120 / \mathrm{min})$; RR, rapid compression rate $(>120 / \mathrm{min}) .{ }^{*}$ and ${ }^{\dagger}$, significantly different.

Table 3. Compression Depth and Rate Cross Tabulation

\begin{tabular}{|c|c|c|c|c|c|}
\hline & & & \multicolumn{2}{|c|}{ Compression rate after training } & \multirow{2}{*}{ Total } \\
\hline & & & $\leq 120 / \min$ & $>120 / \min$ & \\
\hline \multirow{6}{*}{$\begin{array}{l}\text { Compression depth } \\
\text { after training }\end{array}$} & \multirow{3}{*}{$<50 \mathrm{~mm}$} & Students $(n)$ & 53 & 28 & 81 \\
\hline & & $\begin{array}{l}\text { Ratio within } \\
\text { compression depth }\end{array}$ & $65.4 \%$ & $34.6 \%$ & $100.0 \%$ \\
\hline & & adjusted residual & $-2.7^{*}$ & $2.7^{*}$ & \\
\hline & \multirow{3}{*}{$\geq 50 \mathrm{~mm}$} & Students $(n)$ & 109 & 24 & 133 \\
\hline & & $\begin{array}{l}\text { Ratio within } \\
\text { compression depth }\end{array}$ & $82.0 \%$ & $18.0 \%$ & $100.0 \%$ \\
\hline & & adjusted residual & $2.7^{*}$ & $-2.7^{*}$ & \\
\hline \multicolumn{2}{|l|}{ Total } & Students $(n)$ & 162 & 52 & 214 \\
\hline
\end{tabular}

Relationship between compression depth and rate analyzed using data acquired from all students after training. Relationship between compression depth and rate was assessed using Pearson chi-squared tests with Yates continuity correction. Data are shown as $n$ or \%. Chi-squared test data: Chi-squared $=6.600, \mathrm{df}=1, p=0.010$. Adjusted residual: ${ }^{*} p<0.01$.

生が有意に多かった。一方，テンポが 120 回/分以 下の学生群では, 圧迫の深さが $50 \mathrm{~mm}$ 未満の学生 数が有意に低く, 120 回/分超の学生群では $50 \mathrm{~mm}$ 以上の学生が有意に少なかった $(p<0.01)$.

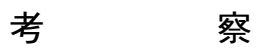

本研究は，学生の胸骨圧迫手技を定量的に評価す ることで，一次救命処置実習における教育効果を解
析し，効果的な指導に応用することを目的とした。

実習後に胸骨圧迫の深さが $50 \mathrm{~mm}$ に達しなかっ た学生は, SC 群で 50\%, DC 群で 19\%であった。

Stiell $ら^{9)}$ は，心拍再開率は深さ $50 \mathrm{~mm}$ 付近がピー ク，1 日生存率及び生存退院率は $50 \mathrm{~mm}$ からプラ トーに達することを報告していることから，実習前 に圧迫の深さが浅かった学生に対しては, 深さの重 要性を強調して重点的に指導を行う必要があると考 
えられる，一方，実習前に $50 \mathrm{~mm}$ 以上の深さで圧 迫できた DC 群において，実習後に $50 \mathrm{~mm}$ 未満と なった学生は，深すぎる圧迫を意識し過ぎたと考え られる。胸骨圧迫の深さが $60 \mathrm{~mm}$ を超えると合併 症のおそれがある10)が，蘇生現場においては致命的 ではない合併症を危惧するあまり，胸骨圧迫が浅く なることは避けなければならない。そのため，胸骨 圧迫が深い傾向にある学生に対しては圧迫の深さの 上限を過度に強調しない指導方法が重要であると考 えられる。一方，心肺停止後の蘇生には冠動脈還流 圧の維持が重要であり, ${ }^{11)}$ そのためには胸骨圧迫の 深さを $50 \mathrm{~mm}$ 以上に保つ必要がある．胸骨圧迫の 深さの質を評価するには，1 分間の胸骨圧迫中で 50-60 mm の間で圧迫できた割合を示す有効率が有 用である，適切な圧迫の深さを修得できた学生の深 さの有効率は，SC 群及び DC 群とも $75 \%$ を超えて おり 1 分間にわたり一定の深さで圧迫を実施してい ると考えられる。

実習後の胸骨圧迫のテンポの全体平均值は, SR 群及び RR 群ともガイドラインの推奨する範囲内で あった（Table 2)。しかし，RR 群では実習後も 120 回/分を超える学生割合が $38.4 \%$ であり, 速す ぎるテンポの修正ができなかつた学生が SR 群に比 ベ多いことが明らかになった。ささに，実習後のテ ンポ平均值が推奨範囲内であった学生群においても,

$\mathrm{RR}$ 群ではテンポの有効率が SR 群に比べ有意に低 く，圧迫毎のテンポを一定に維持できない学生が多 いことが示唆された。したがって，テンポが速い学 生には適切なテンポへの修正に加え，テンポを一定 に保つことに重点をおいて指導を行う必要があると 思われる.

今回の実習では，主にメトロノームのテンポに同 期しながら胸骨圧迫を実施する訓練を取り入れた が，評価時にはメトロノームを用いていない。 Okano ら ${ }^{12)}$ は， 2 人組でメトロノームに同期させて 指をタッピングさせた後メトロノームを停止すると, 2 者のうち速いテンポのほうに対し優先的に修正し てしまうメカニズムが存在することを報告してい る。われわれの実習では，1 教室で 11 体のマネキ ンを同時に使用していることから，テンポの速い学 生の声や行動が目に入ってしまい，評価時には学生 がテンポの速い周囲の学生に合わせてしまった可能 性がある。したがって，潜在的にテンポの速い学生
に適切なテンポを修得させるには，メトロノームな どテンポの指標となるものに同期させる実習を過度 に取り入れず，指導者の口頭指導やフィードバック 装置でのテンポ修正を行うこと，さらにはマネキン の配置についても考慮すべきと考える.

質の高い胸骨圧迫は，100-120 回/分のテンポ13) かつ 50-60 mm の深さで圧迫を実施することである が，テンポが速すぎると適切な胸骨圧迫の深さに到 達する割合が低下する可能性が示されている. ${ }^{14)}$ 本 実習でも，120 回/分を超える速すぎるテンポで実 施した学生群では, 深さが $50 \mathrm{~mm}$ に到達しない学 生数が有意に多いことが明らかとなった。本実習で は，圧迫のテンポと深さの関連性について事前に学 生に説明しなかったが，浅すぎる胸骨圧迫を改善す るには，圧迫の深さのみに注目するのではなく，胸 骨圧迫のテンポを適切な範囲内になるよう同時に指 導する必要があると思われる。

本研究の限界としては, 学生の体重や身長につい ては調査していないことが挙げられる。これまでの 報告では，体重や身長が胸骨圧迫の質に影響を与え ること ${ }^{15,16)}$ が示されている. 今後，学生の身体的特 性を調査し，学修効果との関連を明らかにする必要 があると考えられる。また，今回の研究では，胸骨 圧迫手技のうち圧迫の深さ及びテンポについてのみ の評価であったので，今後は圧迫解除率も測定しテ ンポとの関連性を明らかにすることや AED の使用 方法に関する指導方法の検討も必要であると思われ る.

結論

一次救命処置の実習において，質の高い胸骨圧迫 を修得するには, 胸骨圧迫の深さが浅い学生に対し $50 \mathrm{~mm}$ 以上の深さのみを指標にするのではなく, 適切なテンポでの圧迫を同時に指導することが重要 である。また，胸骨圧迫のテンポが速い学生には， ガイドラインで推奨された範囲内で一定のテンポを 維持する指導を重点的に行う必要がある．個々の学 生に適した指導を行うためには，フィードバック装 置等を用いて実習前にスキルチェックを行うことが 有用であると思われる.

利益相反＼cjkstart開示すべき利益相反はない. 


\section{REFERENCES}

1) The Pharmaceutical Society of Japan, Council for Fostering Human Resources in Pharmacy Education, Ministry of Education, Culture, Sports, Science and Technology (MEXT), Japan, "Model Core Curriculum for Pharmacy Education - 2015 version-,'” March 2018, F(1) 1 Introductory Pharmacy Experience.

2) Fire and Disaster Management Agency of Japan. "Rescue operations, First-aid": 〈https://www.fdma.go.jp/publication/rescue /items/kkkg_h30_01_kyukyu.pdf〉, cited 6 January, 2020.

3) Iwami T., Hiraide A., Nakanishi N., Hayashi Y., Nishiuchi T., Uejima T., Morita H., Shigemoto T., Ikeuchi H., Matsusaka M., Shinya H., Yukioka H., Sugimoto H., Resuscitation, 69, 221-228 (2006).

4) Holmberg M., Holmberg S., Herlitz J., Resuscitation, 47, 59-70 (2000).

5) Japan Resuscitation Council. “2015 Japanese Guidelines for Emergency Care and Cardiopulmonary Resuscitation," IgakuShoin Ltd., Tokyo, 2016.

6) Miyahara H., Journal of Yasuda Women's University, 44, 351-356 (2015).

7) Watanabe T., Itoh K., Yonezawa A., Yakugaku Zasshi, 136, 1319-1323 (2016) .

8) Tokunaga J., Takamura N., Ogata K., Yoshi- da H., Setoguchi N., Sato K., Yakugaku Zasshi, 130, 911-916 (2010).

9) Stiell I. G., Brown S. P., Christenson J., Cheskes S., Nichol G., Powell J., Bigham B., Morrison L. J., Larsen J., Hess E., Vaillancourt C., Davis D. P., Callaway C. W., Crit. Care Med., 40, 1192-1198 (2012).

10) Hellevuo H., Sainio M., Nevalainen R., Huhtala H., Olkkola K. T., Tenhunen J., Hoppu S., Resuscitation, 84, 760-765 (2013) .

11) Paradis N. A., Martin G. B., Rivers E. P., Goetting M. G., Appleton T. J., Feingold M., Nowak R. M., JAMA, 263, 1106-1113 (1990).

12) Okano M., Shinya M., Kudo K., Sci. Rep., 7, 43987 (2017).

13) Abella B. S., Sandbo N., Vassilatos P., Alvarado J. P., O'Hearn N., Wigder H. N., Hoffman P., Tynus K., Vanden Hoek T. L., Becker L. B., Circulation, 111, 428-434 (2005).

14) Monsieurs K. G., De Regge M., Vansteelandt K., De Smet J., Annaert E., Lemoyne S., Kalmar A. F., Calle P. A., Resuscitation, 83, 1319-1323 (2012).

15) Hasegawa T., Daikoku R., Saito S., Saito Y., J. Physiol. Anthropol., 33, 16 (2014).

16) Kikugawa T., Kosseki K., Omatsu K., Kobayashi K., J. Jpn. Soc. Emer. Med., 20, 19 (2017). 